\title{
The Influence of Accelerometer Cut Points on Determining the Percent of Preschool-Age Children Meeting Physical Activity Guidelines
}

Anna Elizabeth Scott

Follow this and additional works at: https://researchrepository.wvu.edu/etd

\section{Recommended Citation}

Scott, Anna Elizabeth, "The Influence of Accelerometer Cut Points on Determining the Percent of Preschool-Age Children Meeting Physical Activity Guidelines" (2015). Graduate Theses, Dissertations, and Problem Reports. 7126.

https://researchrepository.wvu.edu/etd/7126

This Thesis is protected by copyright and/or related rights. It has been brought to you by the The Research Repository @ WVU with permission from the rights-holder(s). You are free to use this Thesis in any way that is permitted by the copyright and related rights legislation that applies to your use. For other uses you must obtain permission from the rights-holder(s) directly, unless additional rights are indicated by a Creative Commons license in the record and/ or on the work itself. This Thesis has been accepted for inclusion in WVU Graduate Theses, Dissertations, and Problem Reports collection by an authorized administrator of The Research Repository @ WVU. For more information, please contact researchrepository@mail.wvu.edu. 
The Influence of Accelerometer Cut Points on Determining the Percent of Preschool-Age Children Meeting Physical Activity Guidelines

Anna Elizabeth Scott, RD, BS

Thesis submitted to the Davis College of Agriculture, Natural Resources, and Design at West Virginia University in partial fulfillment of the requirements for the degree of

MASTER OF SCIENCE

in

Animal \& Nutritional Sciences

Committee Members

Robert Dailey, PhD, Chair

Peter Giacobbi, PhD

Donald Lacombe, $\mathrm{PhD}$

Susan Partington, $\mathrm{PhD}$

Division of Animal \& Nutritional Sciences

Morgantown, WV

2015

Keywords: accelerometers, preschool-age children, cut points, physical activity guidelines, childhood obesity

Copyright 2015 Anna E. Scott 


\begin{abstract}
The Influence of Accelerometer Cut Points on Determining the Percent of Preschool-Age Children Meeting Physical Activity Guidelines
\end{abstract}

\begin{abstract}
Anna E. Scott
Reduced physical activity is thought to be a major contributor to energy imbalance and obesity in children and adolescents. A challenge for researchers is selecting a tool that will accurately measure physical activity, especially in young children. A current tool that is used is an accelerometer. This study had two objectives. The first examined if different sets of accelerometer cut points developed for preschool-age children would produce the same physical activity results when identical raw data were run through them. Through the use of accelerometer data the second objective aimed to determine the percent of children who met the physical activity guidelines for 3 to 5 year olds, which recommend 180 minutes of combined light to vigorous activity each day. Participants wore accelerometers for 7 consecutive days. Raw accelerometer data were run through five sets of accelerometer cut points. A paired t-test was used to compare the minutes per day reported in sedentary, light, moderate to vigorous, and light to vigorous physical activity. The light to vigorous results calculated from the five sets of cut points were used to determine the percent of children who were meeting the physical activity recommendation. While some of the cut points when compared against each other did produce equal results within a particular physical activity threshold, no overall sets of cut points produced the same levels of physical activity across all activity thresholds. Two sets of cut points classified the same percent of participants (10.67\%) as achieving the recommended 180 minutes of activity. A large range of participants (87.33\%-0.33\%) met the recommendations based on the other sets of cut points. The cut points chosen to process raw accelerometer data influenced the reported levels of physical activity.
\end{abstract}




\section{Acknowledgements}

I would like to thank my committee members Dr. Robert Dailey, Dr. Peter Giacobbi, and Dr. Donald Lacombe, and Dr. Susan Partington. Your help with this process was greatly appreciated.

Finally I would like to thank my family and friends. I would not have been able to complete this without your unwavering encouragement and love. 


\section{Table of Contents}

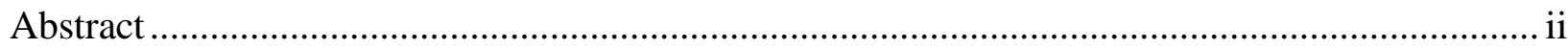

Acknowledgements .............................................................................................

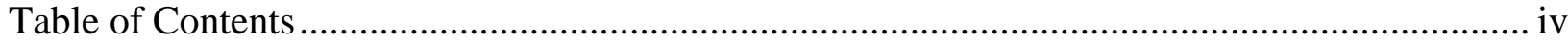

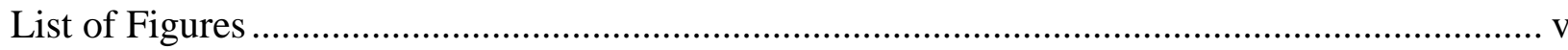

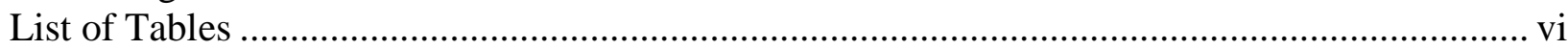

List of Abbreviations ........................................................................................................... vii

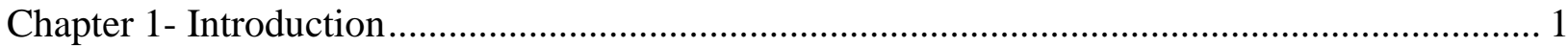

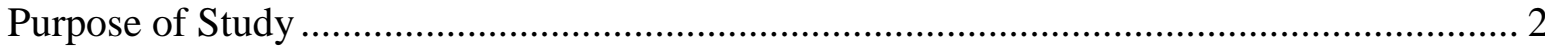

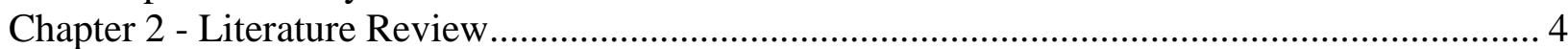

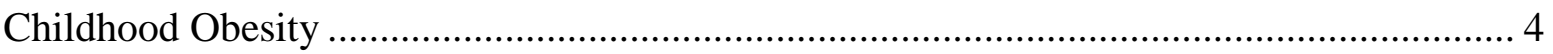

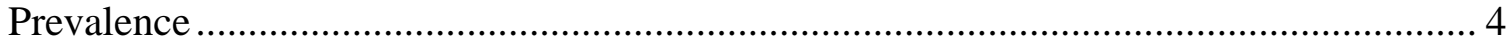

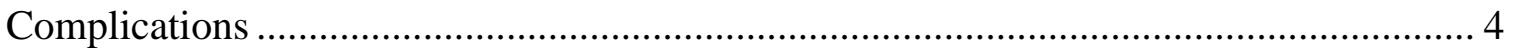

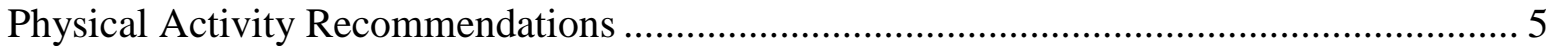

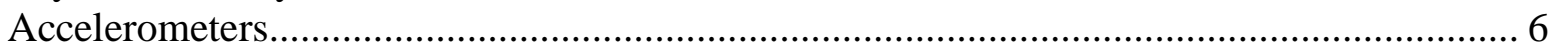

Reported Physical Activity Levels in Young Children..................................................... 13

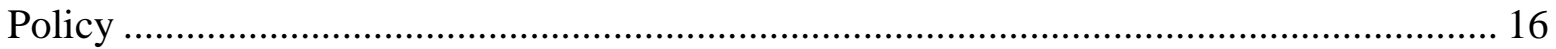

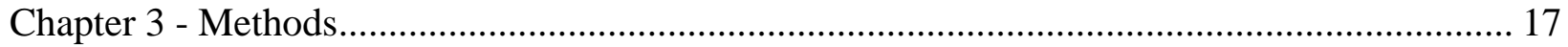

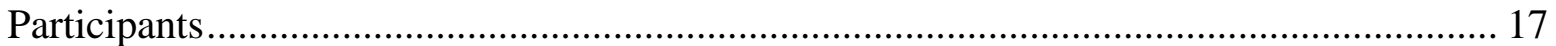

Participant Recruitment .................................................................................... 18

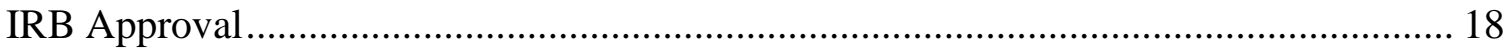

Research Instruments ....................................................................................... 18

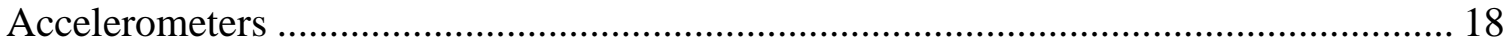

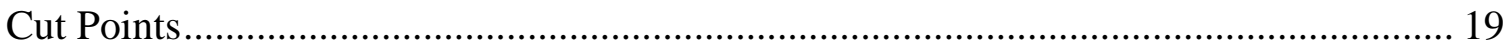

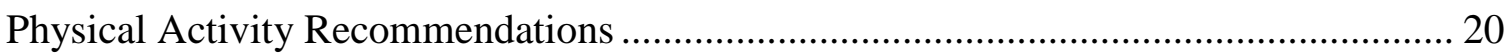

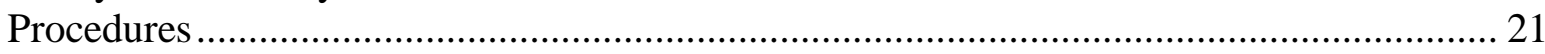

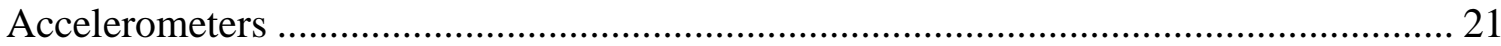

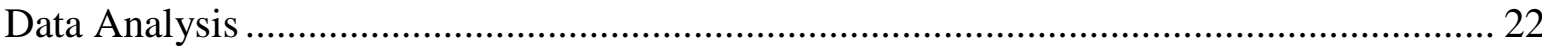

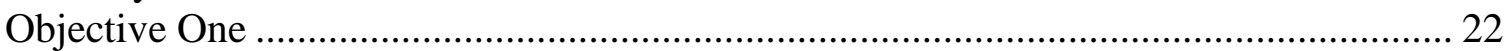

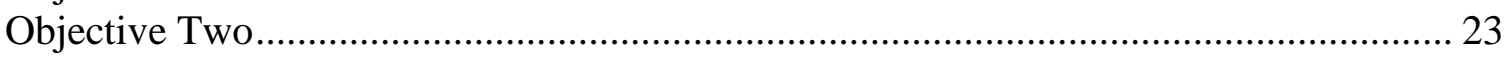

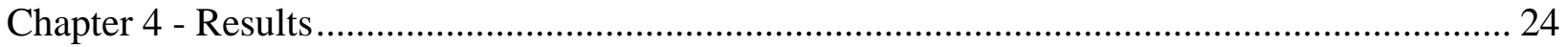

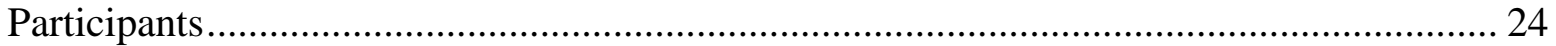

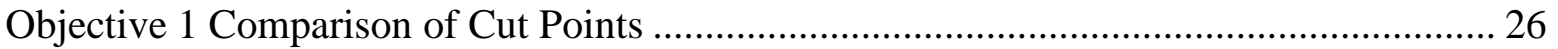

Objective 2 Participants Meeting Physical Activity Recommendations ............................. 29

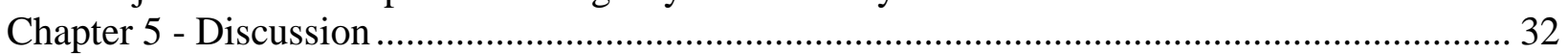

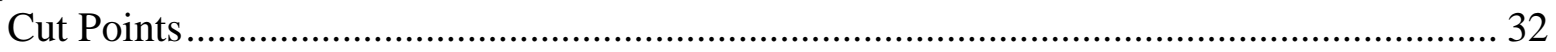

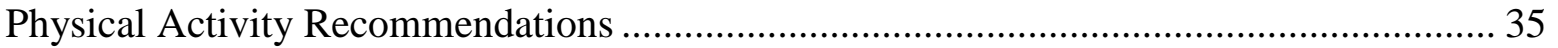

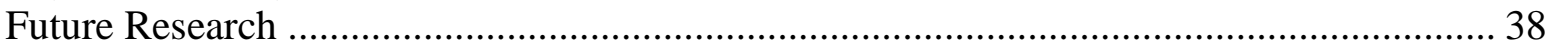

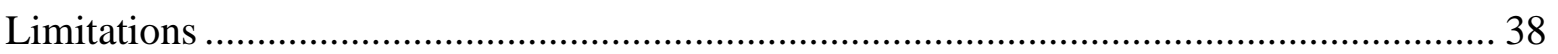

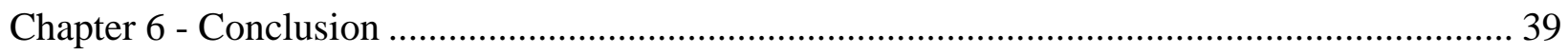

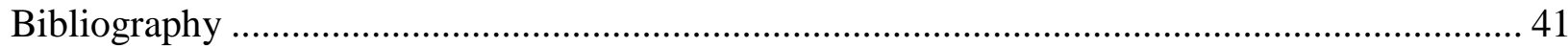

Appendix A - Percent of Time in Activity............................................................................. 45 


\section{List of Figures}

Figure 1. Comparison of Accelerometer Studies: Cut Points ................................................ 8

Figure 2. Participant Inclusion for Analysis ................................................................ 25 


\section{List of Tables}

Table 1. Participant Characteristics within the Study ........................................................ 24

Table 2. Objective 1: Paired t-Test of Accelerometer Cut Points............................................ 26

Table 3. Objective 2: Proportion of Participants Meeting Physical Activity Recommendations. 29

Table 4. Objective 2: T-Test Results Comparing Percent of Participants Who Met

Recommendation by Cut Point Sets ......................................................................... 30

Table 5. Percent of Time Participants Spend in Sedentary and Light to Vigorous Activity by Cut

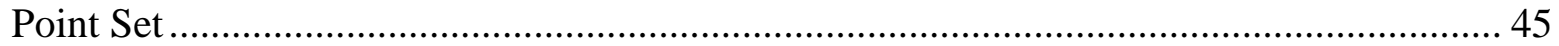




\section{List of Abbreviations}

$\begin{array}{ll}\text { NHANES } & \text { National Health and Nutrition Examination Survey } \\ \text { WHO } & \text { World Health Organization } \\ \text { CDC } & \text { Centers for Disease Control and Prevention } \\ \text { NASPE } & \text { National Association for Sports and Physical Activity } \\ \text { UK } & \text { United Kingdom } \\ \text { CARS } & \text { Children's Activity Rating Scale } \\ \text { CHMS } & \text { Canadian Health Measures Survey } \\ \text { Sed } & \text { Sedentary physical activity } \\ \text { Lt } & \text { Light physical activity } \\ \text { Mod } & \text { Moderate physical activity } \\ \text { Vig } & \text { Vigorous physical activity } \\ \text { MVPA } & \text { Moderate to vigorous physical activity } \\ \text { LMVPA } & \text { Light to vigorous physical activity } \\ \text { SD } & \text { Standard deviation } \\ \text { CI } & \text { Confidence interval } \\ \text { M } & \text { Mean } \\ \text { CSA } & \text { Computer Science and Applications Actigraph } \\ \text { MM } & \text { Mini-Mitter Actiwatch }\end{array}$




\section{Chapter 1- Introduction}

Obesity is a major health issue of our time. The rate of obesity in children is particularly of concern. ${ }^{1}$ According to the 2011-2012 National Health and Nutrition Examination Survey (NHANES) $17 \%$ of youth are obese, and specifically $8.4 \%$ of children aged 2-5 years old are obese. $^{2}$ Obesity in children has been linked with health problems such as hyperlipidemia, hypertension, insulin resistance, respiratory problems, and orthopedic complications, which are diagnoses that were previously only seen in adults. ${ }^{3,4}$ Obese children also have a higher risk of becoming obese adults. ${ }^{3}$

Lifestyle behaviors such as diet and physical inactivity are contributors to energy imbalance and obesity, with reduced physical activity cited as being a major contributor in children and adolescents. ${ }^{1,4}$ Preschool aged children (3-5 year olds) have been identified as an important group to study for early intervention due to a number of reasons, one of which being that, according to Trost et al., it is "a time when physical activity habits are established." $\mathrm{A}$ second reason is that physical activity levels have been seen to decrease with age. Physical activity has been reported to drop by $49 \%$ from age 5 to 12 and by $36 \%$ in adolescents from age 13 to 17 , which makes establishing appropriate physical activity levels in young children important. $^{5}$

Recent reports have recommended that preschool age children achieve at least 180

minutes of combined light, moderate, and vigorous physical activity throughout each day. ${ }^{6,78} \mathrm{~A}$ challenge for researchers is selecting a tool that will accurately measure physical activity, especially in young children, and therefore be able to determine a valid relationship between physical activity and health. ${ }^{9}$ Assessment of physical activity changes is important in tracking the effectiveness of intervention programs and setting policy. ${ }^{10,11}$ 
Researchers can utilize different tools to approximately measure physical activity in preschool aged children including direct observation, motion sensors, heart rate monitors, doubly labeled water, proxy report questionnaires, and accelerometers. ${ }^{12}$ Accelerometers are small electrical devices worn on the hip that record activity counts on vertical, horizontal, and diagonal axes, vector magnitude, and steps taken. ${ }^{13}$ They are used as an objective measure of physical activity, which researchers can then qualify as sedentary, light, moderate or vigorous activity. 3,14 The established thresholds of physical activity intensity called "cut points" were developed from calibration studies. ${ }^{13}$

Evenson et al. reported on advantages to accelerometers, which included elimination of "recall bias, social desirability bias, overcoming language challenges, and literacy difficulties.",14 However, this system of data collection comes with limitations like detection errors, participant compliance issues, user wear time validation, lack of information about the type of activity, and appropriate cut points for the youth population. ${ }^{1,15}$

\section{Purpose of Study}

This study examined two objectives centered around physical activity levels in preschoolage children. The first objective examined the many ways in which raw accelerometer data could be processed. Calibration studies such as the ones conducted by Puyau et al. ${ }^{16}$, Sirard et al. ${ }^{17}$, Pate et al. ${ }^{1}$, Evenson et al. ${ }^{14}$, and Butte et al. ${ }^{13}$ have all produced different sets of cut points. This study ran identical raw accelerometer data through each of the cut point sets to determine if they produced similar results and could thus be used interchangeably to determine physical activity levels.

The second objective was to determine the percent of participants that were meeting the physical activity recommendation of achieving 3 hours of combined light, moderate, and 
vigorous physical activity daily. The minutes per day spent in light to vigorous activity for each participant, which were generated from the five sets of cut points, were used to determine the percent of participants that met the recommendation. Differences between the cut point results were compared for statistical significance. 


\section{Chapter 2 - Literature Review}

\section{Childhood Obesity}

\section{Prevalence}

Obesity has been on the rise in this country for the past 30 years. Increases in prevalence have been seen across the population regardless of socioeconomic status, race, age, sex, or geographic location. ${ }^{18}$ The World Health Organization (WHO) has called overweight and obesity a global epidemic. ${ }^{19}$ The definition of overweight in children is a body-mass index (BMI) in the 85th to 95th percentile for age and sex and a BMI above the 95th percentile for obese. $^{18}$ Obesity is characterized by an excess of body fat. ${ }^{19}$ According to the Centers for Disease Control and Prevention (CDC) approximately 17\% of children age 2-19 in America are obese. $^{20}$ The rate of obesity has tripled in children age $2-5$ years old since the 1970 's. ${ }^{21}$ While the rate for this age range has dropped slightly in recent years, as of 2011-2012 the CDC still reported that $8.4 \%$ of 2 to 5 year olds were obese. ${ }^{20}$

\section{Complications}

Obesity in children has brought on a new wave of complications that were previously rarely seen in the adolescent population. For example, the incidence of type 2 diabetes has increased 10 fold in the last two decades, and fatty liver disease is now seen in one out of three obese children. ${ }^{18}$ Other complications include asthma, sleep apnea, acanthosis nigricans, cardiovascular disorders, skeletal disorders, and psychological disorders. ${ }^{19,21,22}$

What is also concerning are the long term implications of childhood obesity. Researchers have speculated that obese children are anywhere from $70 \%$ to $80 \%$ more likely to become obese adults, which increases their risk of mortality due to type 2 diabetes, cardiovascular disease and digestive diseases. ${ }^{21,23}$ Concerns for decreased life expectancies have been raised within this 
population. $^{21}$ Obese adolescent girls are thought to be two to three times more at risk of dying by middle age than their normal weight counterparts. ${ }^{18}$

Obesity is a complex disease and the root cause is an imbalanced energy intake to energy expenditure. ${ }^{21}$ Genetic variation is thought to play a role in the risk for obesity, but little is known about the exact link of genetic determinants to the disease. ${ }^{19,23}$ Environmental factors like changes in the food environment, sedentary lifestyles, physical activity, and diet are seen as crucial components to the development of obesity. ${ }^{19,23}$

The prevention of childhood obesity has focused on changing environmental factors. Dietary recommendations include limiting sweetened beverages, eating 5 or more fruit and vegetable servings a day, limiting meals away from home, and eating as a family. ${ }^{22}$ Limits on the amount of screen time have been recommended to no more than 2 hours per day. ${ }^{22}$ Physical activity is recommended every day and is defined by raising energy expenditure levels above resting rates. $^{22,24}$

\section{Physical Activity Recommendations}

The physical activity recommendations among preschool age children are not as clear as they are for older children. The CDC recommends that children age 6-17 get 60 or more minutes of moderate to vigorous aerobic physical activity daily, muscle-strengthening physical activity 3 days a week, and bone-strengthening physical activity 3 days a week. ${ }^{25}$ But, the CDC does not provide any recommendations for 3-5 year olds.

The National Association for Sports and Physical Activity (NASPE) recommends that preschoolers get at least 60 minutes of structured physical activity every day and 60 minutes or more of unstructured play. ${ }^{5}$ Structured physical activity was defined as planned movement that was designed and scheduled; however, the intensity of the physical activity was not defined. ${ }^{24}$ 
In recent years the Australia Government Department of Health and Ageing, the United Kingdom (UK) Chief Medical Officers, and the Canadian Physical Activity guidelines

recommend that preschool-age children get at least 3 hours of physical activity each day. ${ }^{8,26}$ The levels of physical activity intensity for those recommendations can be vague such as the one reported by the Australia Government Department of Health and Ageing which simply states that children should be physically active, or they can be more specific as reported by the UK Chief Medical Officers which defined physical activity as including light, moderate, and vigorous activity. $^{8}$

A challenge for researchers is to accurately determine the percent of children who meet these recommendations. One method for tracking compliance with physical activity recommendations is through the use of accelerometers.

\section{Accelerometers}

Accelerometers have become an accepted objective tool for measuring physical activity. The devices are noted for their ability to detect differing levels of physical activity intensity. ${ }^{14}$ Accelerometers record data in raw counts, which then must be interpreted in order to produce meaningful results..$^{14}$

Studies have been conducted to calibrate accelerometer cut points, which act as definitions of physical activity intensity, by comparing raw accelerometer counts against oxygen consumption, direct observation, heart rate levels, doubly labeled water or a combination of these during structured and free-living physical activities. ${ }^{1,13,14,27}$ Each calibration study varied in design and results. There were no established protocols for calibrating accelerometer cut points referenced in any of the studies that were compared. Accelerometer cut points must also be 
calibrated for distinct age ranges, due to differences in physical activity habits seen across the life span. ${ }^{1}$

Studies such as the ones conducted by Puyau et al. ${ }^{16}$, Pate et al. ${ }^{1}$, Evenson et al. ${ }^{14}$, and Butte et al. ${ }^{13}$ used indirect calorimetry as a metabolic measure to compare accelerometer counts against, but each study used the technique in varying ways. Pate et al. and Evenson et al. both used a portable metabolic system, and each calibrated their accelerometer cut points by having children engage in different physical activities that were pre-determined to qualify as sedentary, light, moderate or vigorous activity. ${ }^{1,14}$ The activities that were chosen between the two studies varied and the resulting cut point recommendations differed. For the ActiGraph accelerometer that was used in both studies, Evenson et al. reported cut points as sedentary 0-25 counts/15 seconds, light 26-573 counts/15 seconds, moderate 574- 1002 counts/ 15 seconds, and vigorous over 1003 counts/15 seconds, while Pate et al. reported cut points as moderate 420 counts/15 seconds and vigorous 842 counts/15 seconds. ${ }^{1,14}$ Pate et al. included an unstructured free-play calibration piece to the study in order to cross validate their results, which was not present in the Evenson et al. study. ${ }^{1,14}$

The study conducted by Puyau et al. used room respiration calorimetry as an accelerometer cut point validation tool while their participants engaged in structured physical activity that were predetermined to achieve different levels of physical activity intensity over the course of 6 hours. ${ }^{16}$ Data were collected in 1 minute epochs with participants ranging in age from 6 to 16 years old. ${ }^{16}$

When calibration studies such as Butte et al. and Trost et al. are compared dramatically different calibration methods were used with limited evidence as to which method was superior. ${ }^{13,27}$ Butte et al. used a combination of structured lab visits utilizing heart rate monitors 
and room respiration calorimetry along with a 7 day free-living validation using doubly labeled water, while Trost et al. used a modified Children's Activity Rating Scale (CARS) to code 20 minutes of free-play for comparison to accelerometer counts. ${ }^{13,27}$

Sirard et al. produced three sets of cut points, which were specific to 3, 4, and 5 year olds. ${ }^{17}$ The study was comprised of two parts. The first part calibrated cut points based on five CARS determined structured activities of different intensities. ${ }^{17}$ The second part was a validation study to compare the newly established cut point in a free living environment when compared to direct observation. ${ }^{17}$

Each calibration study used techniques that were justifiable yet still produced different cut points. Figure 1 shows the differences between studies and the cut points that were calculated by each study.

Figure 1. Comparison of Accelerometer Studies: Cut Points

\begin{tabular}{|c|c|c|c|c|c|}
\hline Author & Design & $\begin{array}{l}\text { Measurement } \\
\text { Period }\end{array}$ & Measure of PA & Cut Points & Epoch \\
\hline $\begin{array}{l}\text { Evenson }^{14} \\
(2008)\end{array}$ & $\begin{array}{l}5-8 \text { years } \\
n=30 \\
\text { Females } \\
=63.6 \% \\
\text { Males= } \\
36.4 \% \\
\text { Normal } \\
\text { BMI }\end{array}$ & $\begin{array}{l}\text { Two separate } \\
\text { structured lab } \\
\text { visits: } \\
\text { (Accelerometer } \\
\text { + COSMED) }\end{array}$ & $\begin{array}{l}\text {-ActiGraph } \\
\text { accelerometer } \\
\text {-Actical } \\
\text { Accelerometer } \\
\text {-COSMED } \\
\text { portable } \\
\text { metabolic system }\end{array}$ & $\begin{array}{l}\text { Counts/15 sec } \\
\text { ActiGraph: } \\
\text { SED 0-25 } \\
\text { LT 26-573 } \\
\text { MOD 574- } \\
1002 \\
\text { VIG over } 1003\end{array}$ & 15 seconds \\
\hline
\end{tabular}




\begin{tabular}{|c|c|c|c|c|c|}
\hline $\begin{array}{l}\text { Butte }^{13} \\
(2014)\end{array}$ & $\begin{array}{l}\mathrm{n}=50 \text { model } \\
\text { validation } \\
\text { of CSTS } \\
\text { and MARS } \\
\mathrm{n}=105 \\
\text { model } \\
\text { validation } \\
\text { under free- } \\
\text { living } \\
\text { Healthy }\end{array}$ & $\begin{array}{l}\text { One } 7 \mathrm{hr} \\
\text { structured lab } \\
\text { visit: } \\
\text { (Actiheart+ } \\
\text { ActiGraph } \\
\text { GT3X+ Room } \\
\text { respiration } \\
\text { calorimetry) } \\
\\
\text { Seven free- } \\
\text { living days: } \\
\text { (ActiGraph } \\
\text { GT3X+ } \\
\text { Doubly labeled } \\
\text { water }\end{array}$ & $\begin{array}{l}\text {-Actiheart } \\
\text { (uniaxial } \\
\text { accelerometer + } \\
\text { electrocardiogram } \\
\text { signal processor) } \\
\text {-ActiGraph GT3X } \\
\text { accelerometer } \\
\text {-Room respiration } \\
\text { calorimetry } \\
\text {-Doubly labeled } \\
\text { water }\end{array}$ & $\begin{array}{l}\text { Actigraph } \mathrm{x}- \\
\text { axis: } \\
\text { SED/LT } 240 \\
\text { LT/MOD } 2120 \\
\text { MOD/VIG } \\
4450\end{array}$ & $\begin{array}{l}60 \text { seconds } \\
\text { (15 sec } \\
\text { epochs for } \\
\text { data } \\
\text { acquisition } \\
\text { storage. } \\
\text { Data } \\
\text { collapse } \\
\text { after } \\
\text { download } \\
\text { into } 60 \text { sec } \\
\text { intervals to } \\
\text { align with } \\
\text { calorimeter } \\
\text { data) }\end{array}$ \\
\hline $\begin{array}{l}\text { Pate }^{1} \\
(2006)\end{array}$ & $\begin{array}{l}3-5 \text { years } \\
n=29\end{array}$ & $\begin{array}{l}\text { One structured } \\
\text { lab visit: } \\
\text { (ActiGraph+ } \\
\text { COSMED) }\end{array}$ & $\begin{array}{l}\text {-ActiGraph } \\
\text { Model } 7164 \\
\text { accelerometer } \\
\text {-COSMED } \\
\text { portable } \\
\text { metabolic system }\end{array}$ & $\begin{array}{l}\text { Counts/15 sec } \\
\text { MOD } 420 \\
\text { VIG } 842\end{array}$ & 15 seconds \\
\hline $\begin{array}{l}\text { Trost }^{27} \\
(2012)\end{array}$ & $\begin{array}{l}16-35 \\
\text { months } \\
\mathrm{n}=22 \\
\text { validation } \\
\text { and } \\
\text { calibration } \\
\text { females= }\end{array}$ & $\begin{array}{l}20 \text { min } \\
\text { videotaped } \\
\text { play period }\end{array}$ & $\begin{array}{l}\text { Modified } \\
\text { Children's } \\
\text { Activity Rating } \\
\text { Scale (CARS) }\end{array}$ & $\begin{array}{l}\text { Counts/15 sec } \\
\text { SED 0-48 } \\
\text { LT 49-418 } \\
\text { MOD/VIG } \\
\text { over 418 }\end{array}$ & 15 seconds \\
\hline
\end{tabular}




\begin{tabular}{|c|c|c|c|c|c|}
\hline & $\begin{array}{l}14 \\
\text { males= } 8 \\
\mathrm{n}=18 \\
\text { cross- } \\
\text { validation } \\
\text { females=10 } \\
\text { males= } 8 \\
\text { No physical } \\
\text { limitations }\end{array}$ & & & & \\
\hline $\begin{array}{l}\text { Sirard }^{17} \\
(2005)\end{array}$ & $\begin{array}{l}\text { 3-5 years } \\
\mathrm{n}=16 \text { cut } \\
\text { point } \\
\text { calibration } \\
\mathrm{n}=269 \\
\text { Validation }\end{array}$ & $\begin{array}{l}\text { One structured } \\
\text { lab visit } \\
\text { performing } \\
\text { five structured } \\
\text { activities, } \\
\text { based on the } \\
\text { CARS } \\
\text { intensity } \\
\text { categories, for } \\
3 \text { min each } \\
\\
\text { One to three } \\
\text { direct } \\
\text { observations } \\
\text { while child } \\
\text { wore } \\
\text { accelerometer } \\
\text { at preschool }\end{array}$ & $\begin{array}{l}\text { ActiGraph } \\
\text { accelerometer } \\
\text { Modification of } \\
\text { the Child Activity } \\
\text { Rating Scale } \\
\text { (CARS) } \\
\text { Direct } \\
\text { observation } \\
\text { Palm, Inc. }\end{array}$ & $\begin{array}{l}3 \text { year olds } \\
\text { SED 0-301 } \\
\text { LT 302-614 } \\
\text { MOD 615- } \\
1230 \\
\text { VIG over } 1231 \\
4 \text { year olds } \\
\text { SED 0-363 } \\
\text { LT 364-614 } \\
\text { MOD 812- } \\
1230 \\
\text { VIG over 1235 } \\
\text { 5 year olds } \\
\text { SED 0-398 } \\
\text { LT 399-890 } \\
\text { MOD 891- }\end{array}$ & 15 seconds \\
\hline
\end{tabular}




\begin{tabular}{|c|c|c|c|c|c|}
\hline & & & & $\begin{array}{l}1254 \\
\text { VIG over } 1255\end{array}$ & \\
\hline $\begin{array}{l}\text { Puyau }^{16} \\
(2002)\end{array}$ & $\begin{array}{l}\begin{array}{l}6-16 \text { years } \\
\text { old }\end{array} \\
n=26 \\
\text { Females=12 } \\
\text { Males=14 } \\
\text { Healthy } \\
\text { with } \\
\text { No physical } \\
\text { limitations }\end{array}$ & $\begin{array}{l}\text { One 6hr } \\
\text { structured lab } \\
\text { visit: } \\
\text { (Actigraph+ } \\
\text { Mini-Mitter } \\
\text { Actiwatch } \\
\text { monitors+ } \\
\text { room } \\
\text { respiration } \\
\text { calorimetry+ } \\
\text { microwave } \\
\text { detector+ } \\
\text { telemetry ) } \\
\\
\text { One outdoor } \\
\text { field } \\
\text { measurement }\end{array}$ & $\begin{array}{l}\text { Computer Science } \\
\text { and Applications } \\
\text { Actigraph (CSA) } \\
\text { Mini-Mitter } \\
\text { Actiwatch (MM) } \\
\text { monitors } \\
\text { room respiration } \\
\text { calorimetry } \\
\text { microwave } \\
\text { detector } \\
\text { heart rate by } \\
\text { telemetry }\end{array}$ & $\begin{array}{l}\text { Counts/min } \\
\text { CSA: } \\
\text { SED }<800 \\
\text { LT }<3200 \\
\text { MOD }<8200 \\
\text { VIG }>8200\end{array}$ & 1 minute \\
\hline
\end{tabular}

Many other factors can influence the final physical activity results, such as the epoch length, which is the data acquisition storage period. ${ }^{13}$ Adults are typically recorded in 1 minute epochs as opposed to children, where it is recommended that their counts be recorded in 15 second epochs. ${ }^{1}$ The studies examined used both 15 second epochs and 1 minute epochs to collect data.

Another component to processing accelerometer data includes determining valid wear time when collecting from a free-living study design. Researchers have attempted to refine accelerometer data by eliminating the time the device was not worn before raw data were processed into intensity thresholds. ${ }^{15}$ Troiano et al. defined valid wear time by subtracting non- 
wear time from a 24 hour period. ${ }^{15}$ Non-wear time was defined as "having an interval of 60 minutes with zero activity counts with allowance for 1-2 minutes of counts between 0 and 100. ${ }^{\prime 15}$ The most common non-wear time parameter for this age group was 20 minutes or more of zero activity counts. ${ }^{28}$ An early reference to this concept can be found in a paper by Esliger et al. which claims that 20 minutes or more of zero counts is biologically implausible for this age group. $^{28}$

Once valid wear time is estimated certain factors must be considered, such as how many hours of wear time qualify as a valid day and how many valid days must be present for inclusion into the final analysis. Troiano et al. defined a valid day as having 10 or more hours of valid wear time and in order to qualify for the majority of the analysis participants needed at least 3 valid days out of 7 total collection days. ${ }^{15}$ In the $6-11$ year age range $21.4 \%$ of males wore the accelerometer for 6 days and $23.4 \%$ for 7 days, compared to females in the same age range where $22.2 \%$ wore it for 6 days and $18.6 \%$ for 7 days. ${ }^{15}$ Butte et al. did not reference applying valid wear time parameters to their data, but did report an average wear time of 6.7 days out of the 7 total collection days with $94 \%$ of the children having six or seven days of accelerometer wear. $^{13}$

A study by Penpraze et al. examined 5 and 6 year olds and determined that the most reliable criteria for measuring physical activity was 7 days of wear with 10 hours of wear time per day. ${ }^{29}$ However, they concluded that as little as 3 hours a day for 5 days could produce $70 \%$ reliable physical activity data. ${ }^{29}$ Rich et al. concluded in their study of six thousand 7 year olds that highly reliable results were produced with just 2 days of wear but 10 hours a day. ${ }^{30}$ Hislop et al. claimed 3 days of wear for 7 hours per day would produce reliable results. ${ }^{31}$ Finally a 
meta-analysis by Cliff et al. claimed 3 days of wear could be sufficient in preschool-age children and that 3 hours per day could provide reliable estimates of physical activity. ${ }^{24}$

With the introduction of accelerometers as an objective tool to measure physical activity in free-living environments, the data collected provides new insight into the amounts of physical activity certain segments of the population are engaged in. ${ }^{15}$ Accelerometer data can be interpreted into the amount of time spent in sedentary, light, moderate, or vigorous physical activity. ${ }^{1,13,14}$ Therefore researchers can use the data as a comparison to physical activity guideline recommendations, and determine the percent of population that are meeting or not meeting recommendations.

\section{Reported Physical Activity Levels in Young Children}

Studies, meta-analysis, and government issued reports all contain different conclusions about the amount of physical activity children are engaged in. While some provide only broad generalizations of physical activity levels other provide specific statistics.

One meta-analysis reported that preschool-age children accumulated between 40 to 100 minutes of moderate or vigorous physical activity per day which makes it difficult to determine an accurate measure of how much activity they were getting. ${ }^{32}$ Another report claimed that only half of preschool-aged children were meeting NASPE physical activity recommendations. ${ }^{5}$ Others reported that preschool-aged children exhibit high levels of inactivity and that there has been a decrease in the number of children who are physically active. ${ }^{33,34}$

Different sets of cut points and valid wear time parameters were used throughout many of the preschool-aged physical activity studies. This made it difficult to compare the results. 
A study that examined the effects of allowing children to have more recess time used cut points described by Sirard et al. and determined that the children in their study were sedentary for $90 \%$ of the time that they were awake. ${ }^{35}$

Another study which used Sirard et al. cut points and collected data in 15 second epochs found that $8 \%$ of their participants were achieving 60 minutes of moderate to vigorous activity each day. ${ }^{36}$ This result differed drastically from a study that used Freedson et al. cut points and collected data in 1 minute epochs. ${ }^{12}$ They reported that $90 \%$ of the $5-6$ year olds that participated were achieving 60 minutes of moderate to vigorous physical activity everyday. ${ }^{12}$

One study that looked at the relationship of movement skills to physical activity levels in preschoolers used cut points described by Puyau and Reilly and determined that their participants spent $76.3 \%$ of their time as inactive and only $26.7 \%$ of their time in light to vigorous physical activity. ${ }^{37}$ In a different study which also used cut points described by Puyau and Reilley to process their accelerometer data reported that their participants spent $77 \%$ of their time in sedentary behavior and only $3 \%$ of their total time in moderate to vigorous physical activity. ${ }^{38}$ Both studies collected data over the course of 6 days. ${ }^{37,38}$

Using a combination of cut points developed by Sirard, Trost, Pfeiffer, Dowda, and Pate as a guide for determining physical activity cut point thresholds, one study reported that their participants spent $84.7 \%$ of their time as sedentary and $15.3 \%$ of their time in light to vigorous activity. ${ }^{39}$ Data were collected over 5 days in 15 second epochs. ${ }^{39}$

The CDC provided physical activity results based on national and state levels. The 2014 State Indicator Report on Physical Activity determined that $27.1 \%$ of youth nationally and $31 \%$ of youth in West Virginia were meeting aerobic activity guidelines. ${ }^{25}$ 
A precise and accurate description of preschool age physical activity is still somewhat unknown. ${ }^{32,33}$ Differences in reporting are tied to the fact that there is no precise measure of physical activity in young children. ${ }^{33}$ While advancements in the use of accelerometers have provided valuable data, the device still has limitations.

Accelerometers cannot provide data on the types of activities people are engaged in. Certain activities like bicycling and swimming are not captured by an accelerometer. ${ }^{15}$ As referenced above in the Troiano et al. and Butte et al. studies participant wear compliance can vary. ${ }^{13,15}$ The age of participants can affect cut point accuracy, such as in preschool-age children where it can be difficult to differentiate between moderate and vigorous activity due to the idea that preschoolers do not "attain or sustain high levels of physical exertion for extended periods". ${ }^{13}$ No gold standard cut points have been identified for preschool age children, and cut point definitions can vary dramatically between calibration studies. This can make it difficult to compare the physical activity results reported by studies using different sets of cut points.

Preschool-age children exhibit unique patterns of physical activity when compared to other age groups which makes it particularly difficult to define the amount of activity they get. ${ }^{40}$ Their physical activity is often seen in short unplanned moderate to vigorous burst followed by a recovery period. ${ }^{40}$ They are less likely to participate in planned or structured activity, however they may start to participate in in modified sports like soccer or basketball. ${ }^{24,40}$ Developmentally they are continuing to work on locomotor, stability, and object control skills. ${ }^{24}$ Daytime naps are common and typically last anywhere from a half hour to three hours. ${ }^{24}$

Accelerometers have been used to determine more than the amount of time children spend in light, moderate, and vigorous activity. Accelerometers have been used to identify decreases in physical activity with the progression of age, which has served as a means of 
pinpointing important ages for intervention. ${ }^{15,27}$ Accelerometer studies have allowed researchers to conclude that males participate in higher levels of physical activity when compared to females over almost all age ranges. ${ }^{15}$ They have been used to determine that parents play an influential role on physical activity at this age. It has been shown that when parents participate in more physical activity with their children, their children are more physically active. ${ }^{40}$ Children who spend more time outdoors have been shown to be more physically active by using accelerometers. ${ }^{40}$

\section{Policy}

The recognition of the importance of physical activity for weight maintenance in children has had an impact on policy recommendations. Professional groups like the American Medical Association have proposed increases in physical activity in schools as well as changes to parks and neighborhoods to allow for more physical activity opportunities. ${ }^{22}$ Healthy People 2020 also advocates for more opportunities for physical activity in schools and hopes to increase the proportion of schools that require daily physical education. ${ }^{41}$ Changes in school policy are one way that the initiative hopes to reach their goal of increasing the proportion of children who meet the federal physical activity guidelines. ${ }^{41}$

In order to determine physical activity levels and track changes researchers must collect data on current levels of physical activity. There are many methods and instruments available for gathering that type of data, but no gold standard exists. Accelerometers are one tool for collecting data on physical activity, and they come with a series of pros and cons. 


\section{Chapter 3 - Methods}

This study addressed two objectives. The first objective was to examine the multiple ways in which raw accelerometer data can be processed. There are many calibration studies which have been developed, including ones specific to preschool age children, to classify raw accelerometer counts into meaningful physical activity results. However, there appears to be no consensus on a superior method for processing the data. Each study used slightly different designs for calibrating their accelerometers and subsequently produced varying cut points. This study compared the sets of cut points established by Puyau et al. ${ }^{16}$, Sirard et al. ${ }^{17}$, Pate et al. ${ }^{1}$, Evenson et al. ${ }^{14}$, and Butte et al. ${ }^{13}$ Identical raw accelerometer data that were collected from participants were run through each set of cut points. The reported levels of physical activity produced by each set were measured against each other for statistical significance.

The second objective was to determine the percent of children in the study who met the recommendation of achieving 180 minutes of combined light to vigorous physical activity each day. To accomplish this, identical raw accelerometer data were run through each of the five cut point sets used in objective one. Based on the levels light, moderate, and vigorous physical activity reported by the cut points the percent of participants who achieved the physical activity recommendations was determined. The results produced by each of the five cut point sets were then compared against each other to test if the use of different cut points would generate equivalent proportions of participants who achieved the physical activity recommendations.

\section{Participants}

Data were obtained through part of a larger study which was researching obesity prevention in preschool-age children. Data on participant physical activity were collected 
through the use of accelerometers. The accelerometers were distributed in the fall, winter and spring of each intervention year to three successive cohorts (1.0, 1.5, and 2.0).

\section{Participant Recruitment}

The study was open to children entering pre-kindergarten in Monongalia and Kanawha counties of West Virginia. Families were enrolled during Monongalia and Kanawha prekindergarten round up recruitment events and pre-kindergarten open houses. Finally, teachers were given fliers to place in their students backpacks to take home. Families could contact the study though information provided on the fliers.

\section{IRB Approval}

The research protocol was approved by the International Review Board (IRB) of West Virginia University and consent was obtained from the families before they were allowed to participate in the study.

\section{Research Instruments}

\section{Accelerometers}

This study used the ActiGraph GT3X monitor (ActiGraph, Pensacola, FL). This device is a three axis accelerometer. It recorded data on vertical axis activity acceleration, horizontal axis activity acceleration, and perpendicular axis activity acceleration. ${ }^{43}$ The raw data were converted into the minutes per day and percent of time each participant spent in sedentary, light, moderate and vigorous activity using established sets of cut points in ActiLife version 6 software.

The devices were small, measuring $4.6 \times 3.3 \times 1.5$ centimeters and lightweight, weighing 19 grams. Data were collected in 10 second epochs to capture the maximum amount of sporadic 
activity of the participants but was later scaled up to 60 second equivalents by the ActiLife version 6 program to align with their cut point definitions. ${ }^{44}$

\section{Cut Points}

Five established sets of cut points created from calibration studies were used for processing raw accelerometer data. The cut points selected were created specifically for young children. Evenson et al. developed cut points based on a calibration study using 5-8 year olds. ${ }^{14}$ The study used a combination of ActiGraph accelerometers, Actical Accelerometers, and the COSMED portable metabolic system during structured lab visits to determine their cut points. ${ }^{14}$ The developed cut points for the sedentary threshold were determined to have $95 \%$ sensitivity and $93 \%$ specificity, the moderate threshold cut points had $77 \%$ sensitivity and $81 \%$ specificity, and the vigorous threshold cut points had $68 \%$ sensitivity and $89 \%$ specificity. ${ }^{14}$

The cut points developed by Puyau et al. were developed for slightly older children ranging in age from 6 to 16 years old but have been used in previous studies examining the physical activity of preschool-age children. ${ }^{16,37,38}$ The study consisted of structured lab visits, which utilized room respiration calorimetry, microwave detection, and heart rate monitoring by telemetry as means for developing cut points, as well as structured outdoor activities. ${ }^{16}$

Butte et al. studied 3-5 year olds during a structured lab visit as well time spent in a free living environment. ${ }^{13}$ The study used Actiheart, ActiGraph GT3X accelerometers, room respiration calorimetry, and doubly labeled water for cut point development. ${ }^{13}$ The study found cut points correctly classified rates of sedentary physical activity behavior $82 \%$ of the time, light $58 \%$, moderate $37 \%$, and vigorous $29 \%$ of the time. ${ }^{13}$ Pate el al. also used 3-5 year olds in their study with a design that included a structured lab visit as well as 2 unstructured play times. ${ }^{1}$ Their study used ActiGraph Model 7164 accelerometers and the COSMED portable metabolic 
system. ${ }^{1}$ Pate et al. found their cut points for vigorous activity to have a sensitivity of $66 \%$ and a specificity of $95 \%$, however, when they combined moderate and vigorous cut points the sensitivity was $97 \%$ and the specificity was $82 \%{ }^{1}$

The final study by Sirard et al. calculated cut point for 3-5 year olds by calibrating ActiGraph accelerometers during structured lab visits using CARS developed intensity categories. ${ }^{17}$ Children also were observed during free play to validate the cut points. ${ }^{17}$ The study developed cut points specific to 3,4 , and 5 year olds. This study chose to use the cut points calibrated for 4 year olds. Sedentary physical activity was shown to have a sensitivity of $100 \%$ and a specificity of $100 \%$, moderate activity had a sensitivity of $87 \%$ and specificity of $90 \%$, and vigorous activity had a sensitivity of $100 \%$ and specificity of $80 \% .^{17}$

\section{Physical Activity Recommendations}

The recommendation of achieving 180 minutes of combined light, moderate, and vigorous activity each day was based on three published reports by the Australia Government Department of Health and Ageing, the UK Chief Medical Officers, and the Canadian Physical Activity Guidelines for the Early Years. ${ }^{8,26}$ Recommendations were based on each agencies' review of evidence and consideration of expert opinions, which examined the relationship between adequate levels of physical activity and the prevention of chronic disease. ${ }^{6,7}$

The UK Chief Medical Officers report was specific to preschool-age children. ${ }^{7}$ The Canadian guidelines were developed specifically for children age 0-4 years old, and the Australia Government Department of Health and Ageing recommendations were for 3 to 5 year olds. ${ }^{6,26}$

The UK report on physical activity described light physical activity as including activities such as strolling and standing up, and moderate to vigorous activities as including climbing, swinging, dancing, and running. ${ }^{7}$ 
Children age 0-5 in the past have not been included in population wide physical activity

recommendations. ${ }^{7}$ In recent years agencies have developed and published recommendations for this age group.

\section{Procedures}

\section{Accelerometers}

For this study only those accelerometers that were distributed in November and December of 2012, 2013, and 2014 to cohorts 1.0, 1.5, and 2.0, respectively, were used in analysis. Accelerometer data from all three waves were not examined together because wave two accelerometer data were incomplete. Accelerometer data were missing from the Monongalia County cohort 1.0 wave 2 collection period. Therefore, only the first wave of complete accelerometer data, which were collected at the beginning of the study were analyzed. This also allowed for a baseline description of participant physical activity levels.

Accelerometers were delivered to the study participants at their schools and attached to the child's right hip using an elastic clip belt by research assistants. Participating children were asked to wear the belt every day for 7 consecutive days. Research assistants returned to the schools 7 days after their initial visit to collect the accelerometers. If the child had not returned the accelerometer after the initial collection date, several more attempts were made to collect the device from the school before mailing participants an addressed and postage paid envelope for returning the device. Once the accelerometers were returned they were downloaded to computers using ActiLife version 6 software.

Cohort 1.0 was not compensated for their accelerometer participation, but cohort 1.5 and 2.0 were. 


\section{Data Analysis}

The accelerometer data were downloaded onto computers using the ActiLife version 6 software. Raw accelerometer data were initially cleaned in ActiLife following recommendations provided by Cliff et al. ${ }^{24}$ Non-wear time was defined as 20 consecutive minutes with zero recorded activity counts, which was determined to be biologically implausible by Esliger et al. ${ }^{28}$ Minimum wear time per day was set to three hours in order to qualify as a valid day, and participants had to have a minimum of three valid days to be included in the final statistical analysis. $^{24}$

Once the raw accelerometer data were cleaned they were run through five sets of ActiLife version 6 software cut points, which included those described Puyau et al. ${ }^{16}$, Sirard et al. ${ }^{17}$, Pate et al. ${ }^{1}$, Evenson et al. ${ }^{14}$, and Butte et al. ${ }^{13}$. All of the cut points came pre-installed in ActiLife with the exception of Sirard et al., which had to manually be entered into the software. ActiLife scales all measurements up to 60 seconds, so the cut points for four year olds described in the Sirard et al. study, which were based on 15 second epochs, were multiplied by 4 before they were entered into the software.

The results produced by ActiLife were displayed as the percent of time as well as the total minutes spent in sedentary, light, moderate, and vigorous activity. An average minutes per day spent in each physical activity threshold was calculated for every participant by dividing their total time spent in each activity level by their reported number of valid wear days.

\section{Objective One}

For the first part of the study results produced by the five sets of cut points were compared. Statistical analysis was a paired t-test in Stata 13.1. The mean minutes per day spent 
in sedentary, light, moderate to vigorous, and light to vigorous activity were compared between all five sets while using identical raw accelerometer data.

\section{Objective Two}

The second part of the study was focused on the light to vigorous activity results

produced by the five sets of cut points. From them we were able to determine those participants who engaged in, on average, 180 minutes or more of light to vigorous activity and those who did not. The proportion of participants who met the recommendation versus those who did not was calculated using a proportions estimation. The proportion of participants who accumulated 180 minutes or more of light to vigorous activity were compared across all five sets of cut points to test for statistical significance using a paired t-test. 


\section{Chapter 4 - Results}

\section{Participants}

There were 463 accelerometer entries from the wave 1 accelerometer data collection.

After removing accelerometer data, which contained errors and did not meet the valid wear time parameters, 300 participants remained for the primary analysis. Due to data loss issues within the project only 242 participants had complete data sets available for descriptive statistics. The mean age of the children was 4.65 years (SD 0.42). The minimum age of participants was 3.26 years and the maximum age was 6.49 years. Table 1 displays participant characteristics.

Table 1. Participant Characteristics within the Study

\begin{tabular}{|l|l|}
\hline Sample Size (n) & 242 participants \\
\hline County Distribution & \\
\hline Monongalia & $155(64.05 \%)$ \\
\hline Kanawha & $87(35.95 \%)$ \\
\hline Gender & \\
\hline Male & $128(52.89 \%)$ \\
\hline Female & $114(47.11 \%)$ \\
\hline Participant Age & \\
\hline 3 & $11(4.55 \%)$ \\
\hline 4 & $187(77.27 \%)$ \\
\hline 5 & $40(16.53 \%)$ \\
\hline 6 & $4(1.65 \%)$ \\
\hline Participant Weight Status & \\
\hline Underweight $\left(<5^{\text {th }}\right.$ percentile $)$ & $7(2.89 \%)$ \\
\hline Healthy $\left(<85^{\text {th }}\right.$ percentile $)$ & $160(66.12 \%)$ \\
\hline Overweight $\left(>85^{\text {th }}\right.$ percentile $)$ & $37(15.29 \%)$ \\
\hline Obese $\left(>95^{\text {th }}\right.$ percentile $)$ & $38(15.7 \%)$ \\
\hline
\end{tabular}

For this study $64.95 \%$ of the participants who wore an accelerometer in wave 1 met the minimum wear time inclusion criteria. The mean wear time for accelerometers in the study was 572.15 minutes per day (SD 121.64) for 5.92 days (SD 1.66). Figure 2 displays the justification for choosing the participants who were included in the final analysis. 
Figure 2. Participant Inclusion for Analysis

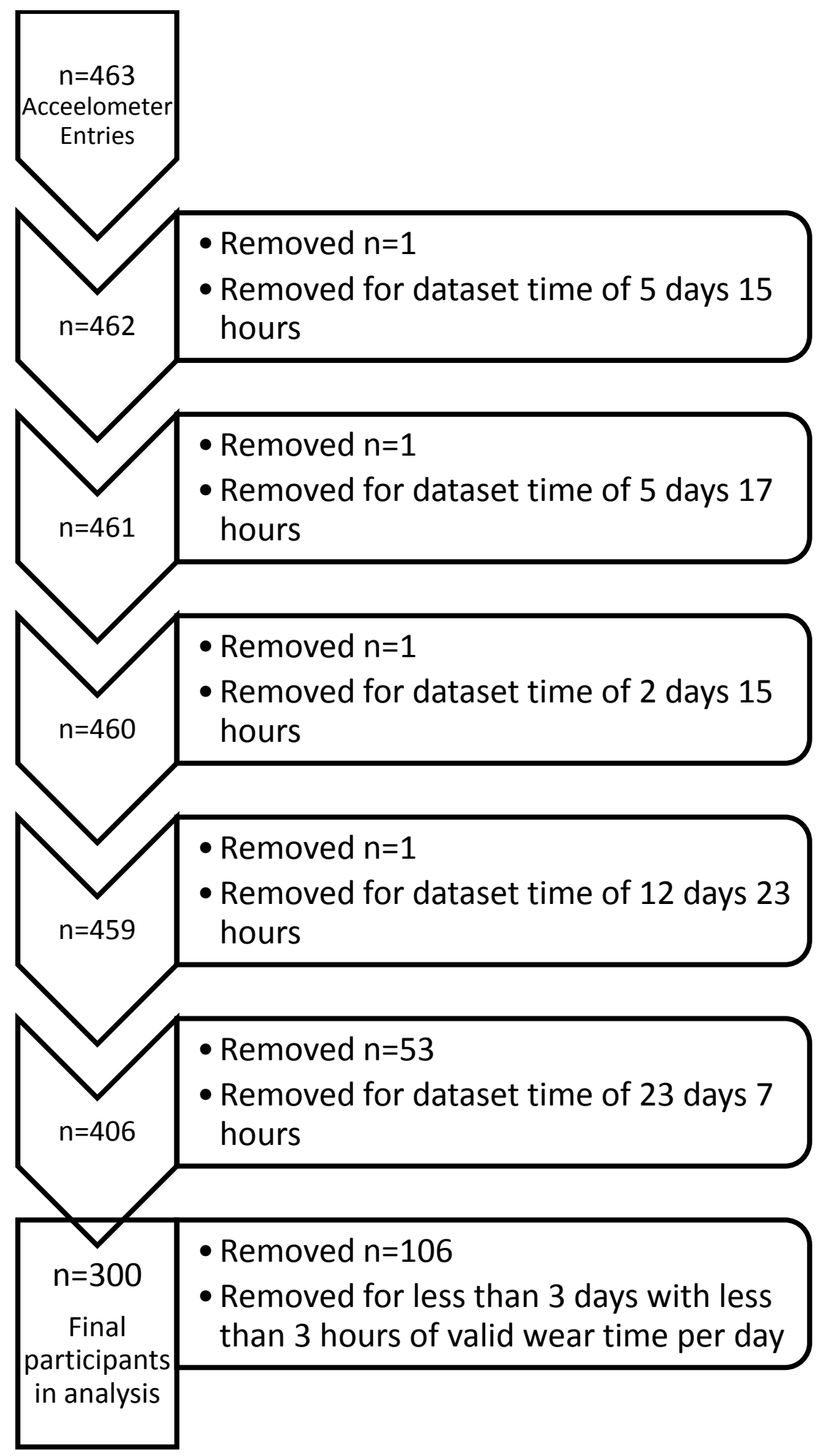




\section{Objective 1 Comparison of Cut Points}

Analysis included accelerometer data from 300 participants who met the valid wear time criteria. A paired t-test was used to compare the minutes per day spent in sedentary, light, moderate to vigorous, and light to vigorous activity produced by each set of cut points. The cut points used were those developed by Puyau et al. ${ }^{16}$, Sirard et al. ${ }^{17}$, Pate et al. ${ }^{1}$, Evenson et al. ${ }^{14}$, and Butte et al. ${ }^{13}$ The resulting mean differences can be seen in Table 2.

Table 2. Objective 1: Paired t-Test of Accelerometer Cut Points

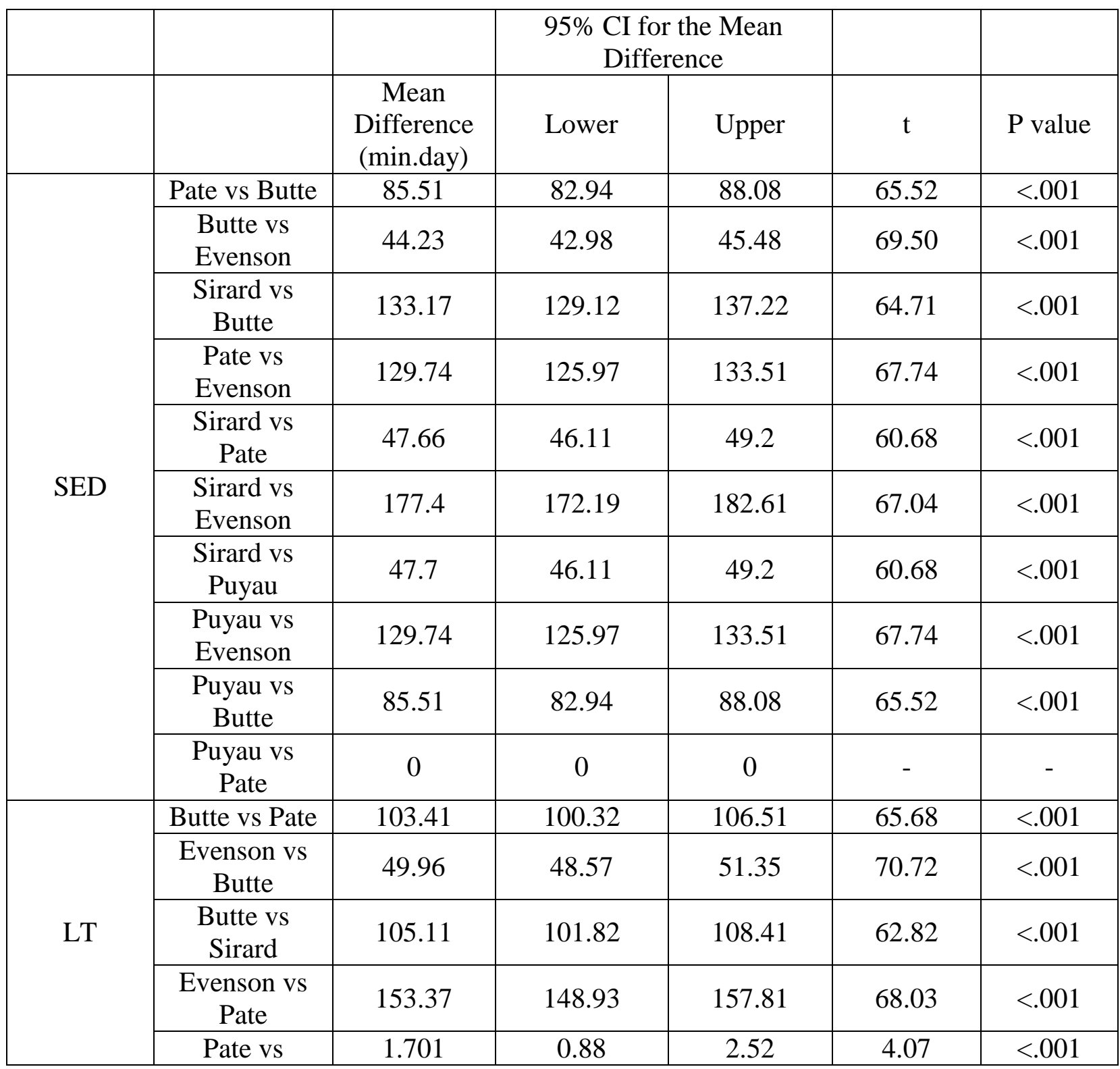




\begin{tabular}{|c|c|c|c|c|c|c|}
\hline & Sirard & & & & & \\
\hline & $\begin{array}{c}\text { Evenson vs } \\
\text { Sirard }\end{array}$ & 155.07 & 150.45 & 159.69 & 66.11 & $<.001$ \\
\hline & $\begin{array}{c}\text { Puyau vs } \\
\text { Sirard }\end{array}$ & 46.92 & 45.4 & 48.44 & 60.72 & $<.001$ \\
\hline & $\begin{array}{c}\text { Evenson vs } \\
\text { Puyau }\end{array}$ & 108.15 & 104.87 & 111.43 & 64.81 & $<.001$ \\
\hline & $\begin{array}{c}\text { Butte vs } \\
\text { Puyau }\end{array}$ & 58.19 & 56.21 & 60.18 & 57.59 & $<.001$ \\
\hline & $\begin{array}{l}\text { Puyau vs } \\
\text { Pate }\end{array}$ & 45.22 & 43.52 & 46.92 & 52.34 & $<.001$ \\
\hline \multirow{10}{*}{ MVPA } & Pate vs Butte & 17.9 & 17.26 & 18.54 & 55.31 & $<.001$ \\
\hline & $\begin{array}{c}\text { Butte vs } \\
\text { Evenson }\end{array}$ & 5.72 & 5.51 & 5.94 & 51.92 & $<.001$ \\
\hline & $\begin{array}{c}\text { Butte vs } \\
\text { Sirard }\end{array}$ & 28.05 & 26.94 & 29.17 & 49.59 & $<.001$ \\
\hline & $\begin{array}{c}\text { Pate vs } \\
\text { Evenson }\end{array}$ & 23.63 & 22.78 & 24.47 & 54.84 & $<.001$ \\
\hline & $\begin{array}{c}\text { Pate vs } \\
\text { Sirard }\end{array}$ & 45.95 & 44.22 & 47.69 & 52.21 & $<.001$ \\
\hline & $\begin{array}{c}\text { Evenson vs } \\
\text { Sirard }\end{array}$ & 22.33 & 21.42 & 23.23 & 48.64 & $<.001$ \\
\hline & $\begin{array}{c}\text { Puyau vs } \\
\text { Sirard }\end{array}$ & 0.73 & 0.7 & 0.77 & 39.22 & $<.001$ \\
\hline & $\begin{array}{c}\text { Evenson vs } \\
\text { Puyau }\end{array}$ & 21.59 & 20.72 & 22.46 & 48.81 & $<.001$ \\
\hline & $\begin{array}{c}\text { Butte vs } \\
\text { Puyau }\end{array}$ & 27.32 & 26.24 & 28.4 & 49.75 & $<.001$ \\
\hline & $\begin{array}{c}\text { Pate vs } \\
\text { Puyau }\end{array}$ & 45.22 & 43.52 & 46.92 & 52.34 & $<.001$ \\
\hline \multirow{9}{*}{ LMVPA } & Butte vs Pate & 85.51 & 82.94 & 88.08 & 65.52 & $<.001$ \\
\hline & $\begin{array}{c}\text { Evenson vs } \\
\text { Butte }\end{array}$ & 44.23 & 42.98 & 45.48 & 69.5 & $<.001$ \\
\hline & $\begin{array}{c}\text { Butte vs } \\
\text { Sirard }\end{array}$ & 133.17 & 129.12 & 137.22 & 64.71 & $<.001$ \\
\hline & $\begin{array}{c}\text { Evenson vs } \\
\text { Pate }\end{array}$ & 129.74 & 125.97 & 133.51 & 67.74 & $<.001$ \\
\hline & $\begin{array}{c}\text { Pate vs } \\
\text { Sirard }\end{array}$ & 47.66 & 46.11 & 49.20 & 60.68 & $<.001$ \\
\hline & $\begin{array}{c}\text { Evenson vs } \\
\text { Sirard } \\
\end{array}$ & 177.4 & 172.19 & 182.61 & 67.04 & $<.001$ \\
\hline & $\begin{array}{c}\text { Puyau vs } \\
\text { Sirard }\end{array}$ & 47.66 & 46.11 & 49.20 & 60.68 & $<.001$ \\
\hline & $\begin{array}{c}\text { Evenson vs } \\
\text { Puyau }\end{array}$ & 129.74 & 125.97 & 133.51 & 67.74 & $<.001$ \\
\hline & Butte vs & 85.51 & 82.94 & 88.08 & 65.52 & $<.001$ \\
\hline
\end{tabular}




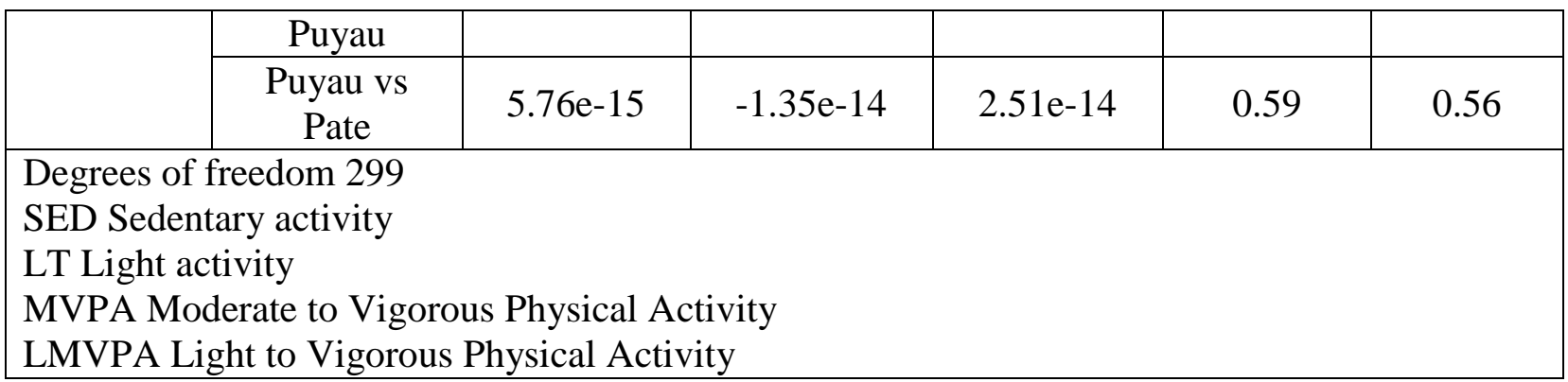

The results illustrate that only a couple of cut point definitions produced the same levels of physical activity. The first cut point comparison that did not produce a statistically different mean difference was between Puyau sedentary $(M=441.67, S D=96.27)$ and Pate sedentary ( $M=441.67, S D=96.27)$, which had a mean difference equal to zero. The second cut point comparison that did not produce a statistically different mean difference was between Puyau light to vigorous $(\mathrm{M}=130.48, \mathrm{SD}=40.48)$ and Pate light to vigorous $(\mathrm{M}=130.48, \mathrm{SD}=40.48)$, $\mathrm{t}(299)=0.59, \mathrm{p}<.56$.

There were statistically significant differences between Puyau light $(\mathrm{M}=104.09, \mathrm{SD}=$ 31.03) and Pate light $(\mathrm{M}=58.87, \mathrm{SD}=16.86), \mathrm{t}(299)=52.34, \mathrm{p}<.001$ as well as between Puyau moderate to vigorous $(\mathrm{M}=26.39, \mathrm{SD}=11.82)$ and Pate moderate to vigorous $(\mathrm{M}=71.61, \mathrm{SD}=$ 25.65), $\mathrm{t}(299)=52.34, \mathrm{p}<.001$. There were statistically significant differences between the remainder of the cut point comparisons across all activity levels.

The results showed a large range in the mean minutes per day within the activity thresholds between the five sets of cut points. The most extreme differences in mean minutes per day was between Sirard sedentary $(\mathrm{M}=489.33, \mathrm{SD}=105.06)$ and Evenson sedentary $(\mathrm{M}=$ 311.93, $\mathrm{SD}=75.2), \mathrm{t}(299)=67.04, \mathrm{p}<.001$ as well as Evenson light to vigorous $(\mathrm{M}=260.22, \mathrm{SD}=$ 68.77) and Sirard light to vigorous $(\mathrm{M}=82.82, \mathrm{SD}=28.63), \mathrm{t}(299)=67.04, \mathrm{p}<.001$. The smallest mean differences in minutes per day were between the results described by Butte moderate to 
vigorous $(M=53.7, S D=20.59)$ and Evenson moderate to vigorous $(M=47.98, S D=18.88)$,

$\mathrm{t}(299)=51.92, \mathrm{p}<.001$ as well as Puyau moderate to vigorous $(\mathrm{M}=26.39, \mathrm{SD}=11.82)$ and Sirard moderate to vigorous $(\mathrm{M}=25.65, \mathrm{SD}=11.55), \mathrm{t}(299)=39.22, \mathrm{p}<.001$.

While some of the cut points within a particular physical activity threshold did produce equal results when they were compared against each other there were no overall sets of cut points that produced the same levels of physical activity across all activity thresholds. Therefore, different sets of cut point will not equally classify all levels of physical activity. Furthermore, sets of cut points cannot be used interchangeably and physical activity results generated from a study can differ depending on choice of cut points.

\section{Objective 2 Participants Meeting Physical Activity Recommendations}

To answer the second part of the study identical raw accelerometer data were analyzed using five sets of cut points developed by Puyau et al. ${ }^{16}$, Sirard et al. ${ }^{17}$, Pate et al. ${ }^{1}$, Evenson et al. ${ }^{14}$, and Butte et al. ${ }^{13}$. Focusing on the levels of light to vigorous physical activity produced by each set of cut points enabled classifying participants into those who did and did not obtain the recommended 180 minutes of physical activity a day. We then calculated the proportion of participants, using each of the five sets of cut points, who met the recommendation to those that did not. The proportional results can be seen in table 3 .

Table 3. Objective 2: Proportion of Participants Meeting Physical Activity Recommendations

\begin{tabular}{|c|c|c|}
\hline Cut Point & $\begin{array}{c}\text { \% 180 minutes or more } \\
\text { LMVPA }(\mathrm{CI})\end{array}$ & $\begin{array}{c}\text { \% under } 180 \text { minutes } \\
\text { LMVPA }(\mathrm{CI})\end{array}$ \\
\hline Butte & 74 & 26.00 \\
& $(68.71,78.67)$ & $(21.32,31.29)$ \\
\hline Sirard & 0.33 & 99.67 \\
& $(0.05,2.35)$ & $(97.65,99.95)$ \\
\hline Evenson & 87.33 & 12.67 \\
& $(83.04,90.66)$ & $(9.34,16.96)$ \\
\hline Pate & 10.67 & 89.33 \\
& $(7.63,14.72)$ & $(85.28,92.37)$ \\
\hline
\end{tabular}




\begin{tabular}{|l|c|c|}
\hline \multicolumn{1}{|c|}{ Puyau } & \multicolumn{1}{|c|}{$\begin{array}{c}10.67 \\
(7.63,14.72)\end{array}$} & $(85.28,92.37)$ \\
\hline $\begin{array}{l}\text { CI 95\% confidence interval } \\
\text { Number of Observations 300 } \\
\text { LMVP light to vigorous physical activity }\end{array}$ \\
\hline
\end{tabular}

A paired t-test was conducted to test for similarities between the percent of participants who met the recommendation within each set of cut points. The results of the test can be seen in Table 4.

Table 4. Objective 2: T-Test Results Comparing Percent of Participants Who Met Recommendation by Cut Point Sets

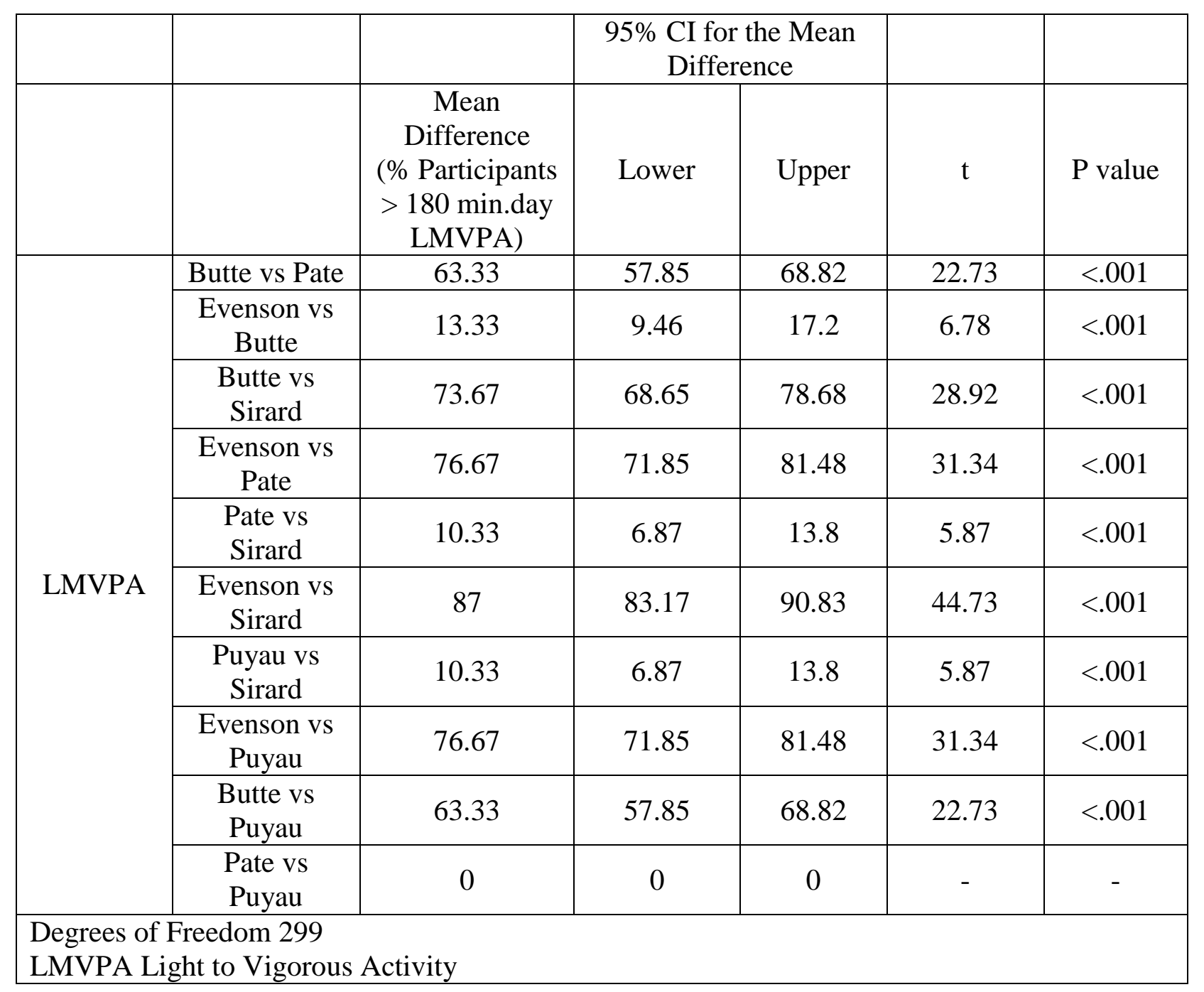


The results show that Pate $(M=10.67 \%, S D=30.92 \%)$ and Puyau $(M=10.67 \%$, $\mathrm{SD}=30.92 \%$ ) classified the same percent of participants as achieving the recommended 180 minutes of light to vigorous activity per day.

There were statistically significant differences between the other comparisons. The largest difference in the percent of children who met the recommendation could be seen between Evenson $(\mathrm{M}=87.33 \%, \mathrm{SD}=33.31 \%)$ and Sirard $(\mathrm{M}=0.33 \%, \mathrm{SD}=5.77 \%), \mathrm{t}(299)=44.73, \mathrm{p}<.001$. 


\section{Chapter 5 - Discussion}

This study investigated two objectives. The first objective was to determine if different sets of cut points developed for preschool-age children would produce the same physical activity results when identical raw data is processed through them. The second objective was to calculate the percent of participants who were reaching the physical activity recommendation of 180 minutes a day of light to vigorous activity.

\section{Cut Points}

According to the results of this study different sets of cut points did not result in equal reporting across all physical activity levels. This study did however show that the cut points developed by Pate et al. ${ }^{1}$ and Puyau et al. ${ }^{16}$ produced the same results when comparing levels of sedentary behavior. The sedentary activity threshold was set to 0-799 counts per minute for both sets in ActiLife. This resulted in identical classification of sedentary activity when raw accelerometer data were analyzed. Pate et al. ${ }^{1}$ and Puyau et al. ${ }^{16}$ also produced the same levels of light to vigorous activity. By collapsing the light, moderate, and vigorous activity thresholds into one category the results masked the differences in cut points for the individual activity levels.

The light, moderate, and vigorous cut points for Pate et al. ${ }^{1}$ in ActiLife were set to 8001679 counter per minute, 1680-3367 counts per minute, and 3368 counts per minute and above respectively. These varied from the light, moderate, and vigorous cut points for Puyau et al. ${ }^{16}$ which were 800-3199 counts per minute, 3200-8199 counts per minute, and 8200 counts per minute and above respectively. 
The discrepancies in cut points between Puyau et al. ${ }^{16}$ and Pate et al. ${ }^{1}$ were obvious when the results of the paired t-test were examined. A mean difference of 45 minutes could be seen between the two sets in their reporting of light activity as well as moderate to vigorous activity.

The variation in study calibration designs might have accounted for the cut point disagreement seen between the sets. For one thing the participants in the Pate et al. study were 3 to 5 years old, while the participants in the Puyau et al. study were 6 to 16 years old. ${ }^{1,16}$

The activities chosen to represent the physical activity thresholds also differed. Puyau et al. calibrated sedentary behavior with activities like playing Nintendo, painting while seated, and playing with toys on the floor; light activity with a warm up exercise and walking on a treadmill at a speed of 2.5 miles per hour; moderate activity with bouncing a ball, using a hula hoop, jumping jacks, and walking on a treadmill at a speed of 3.5 miles per hour; and vigorous activity with jogging on a treadmill at a speed a speed of 4.5 miles per hour. ${ }^{16}$ Pate et al. described having participants partake in three different speeds of walking or jogging for their cut point calibration. ${ }^{1}$ The two speeds of walking were undertaken at 2 miles per hour and 3 miles per hour while jogging was performed at 4 miles per hour. ${ }^{1}$

Discrepancies in calibration techniques could be seen between the other studies. The study conducted by Sirard et al. utilized CARS to choose activities which had been identified as falling into categories with significantly different energy expenditures. ${ }^{17}$ The activities included sitting and talking, walking at an average speed of 2 miles per hour, walking at an average speed of 2.7 miles per hour, and jogging at an average speed of 4.3 miles per hour. ${ }^{17}$

While Sirard et al. and Pate et al. had similar activities that were used within the two studies they collected data in different ways. Sirard et al. calibrated their accelerometer cut points while participants engaged in activities that were designed to meet the definition of 
sedentary, light, moderate, and vigorous activity based on CARS defined activity thresholds. ${ }^{17}$

The study then used direct observation to validate their developed cut points. ${ }^{17}$ Pate et al. used a portable metabolic system to measure oxygen consumption during both the calibration portion of their study as well as the validation portion of their study. The relationship between maximal oxygen uptake and accelerometer counts during each structured activity was examined to produce the accelerometer count cut points for each physical activity level. ${ }^{1}$

Evenson et al., like Pate et al., used a portable metabolic system to record oxygen consumption for accelerometer calibration, however the ages of the participants were slightly older: 5 to 8 years old. ${ }^{14}$ Along with oxygen consumption the study included a heart rate measurement while children preformed activities such as climbing stairs, dribbling a ball, watching a DVD, coloring, and walking or jogging on a treadmill. ${ }^{14}$

The study conducted by Butte et al. used heart rate measurements to determine accelerometer cut points. By using established heart rate cut points for sedentary, light, moderate, and vigorous activity the study was able to determine accelerometer count thresholds for each activity level. ${ }^{13}$

Each calibration study used different techniques for determining their cut point thresholds and as a result the cut points between the studies varied. This resulted in each set of cut points producing different reports of light and moderate to vigorous physical activity, and nearly all sets of cut points producing different reports of sedentary and light to vigorous activity.

What is more is there seems to be little consensus on a superior set of cut points or even calibration design. All of the cut points were created from validated calibration studies, and were all appropriate for the classification of physical activity for participants within this study. 
Yet the choice of cut points would result in different reports of physical activity levels for this study.

\section{Physical Activity Recommendations}

The differences in the level of physical activity which were reported by the sets of cut points in objective 1 were mirrored in the results of objective 2 when the percent of children who were meeting the recommended 180 minutes of combined light to vigorous activity was determined. The percent of participants who met the recommendation was the same between Puyau et al. ${ }^{16}$ and Pate et al. ${ }^{1}$ The cut point definitions for light to vigorous activity were the same for the two sets at 800 counts per minute or above in ActiLife.

The percent of participants who met the recommendation varied widely between all of the other sets of cut points. The cut points calibrated by Butte et al. ${ }^{13}$ determined that $74 \%$ of the participants met or exceeded 180 minutes of light to vigorous activity, with the cut point for activity set at 240 counts per minute in ActiLife. Sirard et al. ${ }^{17}$ cut points determined less than $1 \%$ of the participants met the recommendation with their ActiLife threshold for activity over sedentary set at 1453 counts per minute. Evenson et al. ${ }^{14}$ determined the highest percent of participants meeting the 180 minute recommendation at $87 \%$. The ActiLife threshold for any activity above sedentary was set to 101 counts per minute.

Other studies have investigated the percent of children who meet various physical activity guidelines. In one study, which also examined the percent of children who were meeting the Australia Government Department of Health and Ageing, the United Kingdom (UK) Chief Medical Officers, and the Canadian Physical Activity guideline recommendations, used the cut points developed by Evenson et al. to process raw accelerometer data into physical activity

results. $^{45}$ The study determined that $98.4 \%$ of the 4 to 6 year olds met the recommendation, 
which was in contrast to this study where only $87 \%$ of the children met the recommendation when using Evenson et al. cut points. ${ }^{45}$

The study used other parameters around the accelerometer data, which could have influenced the final results. Unlike this study which recorded accelerometer counts in 10 second epochs and included children with 3 hours of valid wear time into the data analysis the study by Vale et al. recorded activity in 5 second epochs and required 10 hours of valid wear time per day. ${ }^{45}$ It is difficult to know if the children in the two studies were indeed engaging in different amounts of physical activity or if the difference in data collection and processing accounted for the discrepancies in the results

A Canadian study, which aimed to determine the percent of 3 to 4 years olds in Canada who were meeting the 180 minute physical activity recommendation, used data collected from the Canadian Health Measures Survey (CHMS). ${ }^{46}$ The cut point of 100 counts per minute was chosen to differentiate sedentary behavior from light to vigorous physical activity. ${ }^{46}$ Data were collected in 60 second epochs. ${ }^{46}$ The study concluded that $84 \%$ of Canadian children were meeting the physical activity recommendation. These results were similar to those determined in this study when using Evenson et al. cut points which also used a 100 count per minute sedentary activity upper threshold. ${ }^{14,46}$

The choice of physical activity guidelines that were used in studies to determine the percent of participant adherence varied. The physical activity recommendations established by NASPE were also used in a number of studies. The recommendations state that preschool age children should engage in 120 minutes of activity each day, which includes 60 minutes of structured activity and 60 minutes or more of unstructured activity. ${ }^{47}$ The NASPE recommendations left room for interpretation within the phasing and therefore different studies 
defined the recommendations in a number of ways. ${ }^{47}$ Some of the interpretations included 120 minutes of light to vigorous activity each day, 60 minutes of moderate to vigorous physical activity each day, or 120 minutes of moderate to vigorous physical activity each day. ${ }^{47,48,49}$

One study used cut points described by Sirard et al. to determine that only $26 \%$ of their participants reached the recommended 120 minutes of light to vigorous physical activity while another study, which used cut points described by Reilly et al., determined on weekdays that $74.3 \%$ of the children in their study met recommendations. ${ }^{48,49}$

A study, which used the 120 minutes of light to vigorous activity definition, found that between $13 \%$ to $99.5 \%$ of their participants met the recommendation depending on which cut point classification was used. ${ }^{47}$ Across multiple studies a range of $0.0 \%$ to $95.7 \%$ of participants were determined to accumulate 60 minutes or more of moderate to vigorous activity. ${ }^{47,48,49}$

This study was in keeping with current research, which shows a wide range in the percent of participants meeting physical activity guidelines based on the choice of cut points. Between $0.33 \%$ and $87.33 \%$ of the participants in this study met the recommendation of 180 minutes of daily combined light to vigorous activity. Based on the literature no gold standard exists therefore, results calculated in this study could justifiably be used to describe the percent of participants meeting the recommendation.

One thing that does seem to be consistent across all studies regardless of the cut points used is that preschool age children partake in more sedentary behavior than all other activity levels combined. The amount of time children in this study spent in sedentary behavior ranged from $54.52 \%$ to $85.52 \%$ of their total recorded time. Other studies have reported children spending between $50 \%$ to $84.7 \%$ of their time in sedentary behavior. ${ }^{46,48,49}$ 


\section{Future Research}

This study examined whether accelerometer cut points developed from calibration studies could be used interchangeably to produce similar reports of time spent in physical activity. After the analysis, they cannot be used interchangeably, except in certain circumstances when multiple activity levels are collapsed. No set of cut point was a superior choice to others for processing data. Therefore, it must be understood that any analysis conducted with one chosen set of cut points could produce results that would have be different had another set of cut points been used.

This study also aimed to define the percent of participants that met the 180 minute daily combined light to vigorous activity recommendation set forth by the Australia Government Department of Health and Ageing, the UK Chief Medical Officers, and the Canadian Physical Activity Guidelines for the Early Years. ${ }^{8,26}$ A range of $0.33 \%$ to $87.33 \%$ of participants met the recommendation. This highlights the need for a standardized set of guidelines that can be referenced when collecting and processing accelerometer data. It is justifiable to use a wide range of cut point classifications which have been developed and validated. However, it is not clear which one most accurately represents the true level of physical activity within a sample. Future studies should be conducted to validate a superior set of cut points.

\section{Limitations}

This study was not able to definitively describe the percent of participants within the study who were meeting physical activity guidelines due to the wide range of results produced by the varying set of cut points. In order to report a single statistic the study must acknowledge that if any cut points, other than those described by Pate et al. and Puyau et al., are used they will produce statistically different results. 


\section{Chapter 6 - Conclusion}

Physical activity is connected to energy balance, weight, and disease prevention ${ }^{1,4}$ Guidelines have been established to define the amount of physical activity that different age groups within the population should be meeting in order to reduce the risk of chronic disease. ${ }^{8,26}$ It is important to be able to accurately describe the amount of activity children are engaging in every day in order to determine the percent of the population who are not meeting the recommendations and are therefore at an increased risk of developing a chronic disease. ${ }^{47}$.

Accelerometers are one tool to collect data on physical activity. Accelerometer data have been used to classify physical activity into sedentary, light, moderate, and vigorous thresholds, but there are many methods available for processing data. This study compared five different sets of calibrated cut points to determine if they produced statistically equal classifications of physical activity. Next the study used the light to vigorous results produced by each set of cut points to determine the percent of participants who were meeting the preschool-age physical activity recommendation of 180 minutes of light to vigorous physical activity each day.

The results produced by this study indicate that the five sets of cut point calibrated by Puyau et al. ${ }^{16}$, Sirard et al. ${ }^{17}$, Pate et al. ${ }^{1}$, Evenson et al. ${ }^{14}$, and Butte et al. ${ }^{13}$ produced different amounts of time spent in physical activity across all activity thresholds. However, the cut points developed by Puyau et al. ${ }^{16}$ and Pate et al. ${ }^{1}$ were able to classify the same levels of sedentary and light to vigorous physical activity. When the light to vigorous results from the five sets of cut points were used to determine those participants who had over 3 hours of physical activity Puyau et al. ${ }^{16}$ and Pate et al. ${ }^{1}$ classified the same percent of children as meeting the recommendation. None of the other cut point sets produced the same percent of participants who met the recommendation. 
The techniques used to determine accelerometer cut points in each of the calibration studies varied. Subsequently the majority of cut points that designated activity thresholds were different between Puyau et al. ${ }^{16}$, Sirard et al. ${ }^{17}$, Pate et al. ${ }^{1}$, Evenson et al. ${ }^{14}$, and Butte et al. ${ }^{13}$. The differences between the cut point definitions where enough to produce widely varying reports of the minutes per day participants spent in sedentary, light, moderate, and vigorous activity.

These results suggest that Puyau et al. ${ }^{16}$ and Pate et al. ${ }^{1}$ will classify the same percent of the population as meeting the physical activity recommendation for 3 to 5 year olds to obtain 180 minutes of light to vigorous activity each day. However, the results also indicate that the choice of cut points in most cases will affect the levels of physical activity reported. This helps to highlight the necessity of developing guidelines for the processing and analysis of raw accelerometer data.

Any further physical activity analysis conducted should anticipate that there is no one correct set of cut points with which to use and the choice of cut points will affect the final reports. 


\section{Bibliography}

1) Pate RR, Almeida MJ, McIver KL, Pfeiffer KA, Dowda M. Validation and calibration of an accelerometer in preschool children. Obesity. 2006; 14(11): 2000-6

2) Ogden CL, Carroll MD, Kit BK, Flegal KM. Prevalence of Childhood and Adult Obesity in the United States, 2011-2012. JAMA. 2014; 311(8): 806-14

3) Trost SG, Sirard JR, Dowda M, Pfeiffer KA, Pate RR. Physical activity in overweight and nonoverweight preschool children. Int J Obes Relat Metab Disord. 2003; 27(7): 834-9

4) Pinard CA, Yaroch AL, Hart MH, Serrano EL, McFerren MM, Estabrooks PA. The Validity and reliability of the Comprehensive Home Environment Survey (CHES). Health Promot Pract. 2014: 5(1): 109-17

5) Tucker P. The Physical Activity Levels of Preschool-aged Children: A systematic Review. Early Child Res Q. 2008; 23: 547-58

6) Australia's Physical Activity and Sedentary Behaviour Guidelines. Australian Government Department of Health Web Site.

http://www.health.gov.au/internet/main/publishing.nsf/content/health-pubhlth-strateg-physact-guidelines\#npa05. Updated July 10, 2014. Accessed September 23, 2015

7) Department of Health, Physical Activity, Health Improvement and Protection. Start Active, Stay Active: A report on physical activity from the four home countries' Chief Medical Officers. https://www.gov.uk/government/publications/start-active-stay-active-a-report-onphysical-activity-from-the-four-home-countries-chief-medical-officers. Published July 11, 2011. Accessed September 24, 2015

8) Pate RR, O’Neill JR. Physical Activity Guidelines for Young Children: An Emerging Consensus. Arch Pediatr Adolesc Med. 2012;166(12):1095-1096

9) Kowalski KC, Crocker P, Faulkner RA . Validation of the Physical Activity Questionnaire for Older Children. Pediatr Exerc Sci. 1997; 9(2): 174-86

10) González-Gil EM, Mouratidou T, Cardon G, et al. Reliability of primary caregivers reports on lifestyle behaviours of European pre-school children: the ToyBox-study. Obes Rev. 2014; 15: 61-6

11) Van Cauwenberghe E, Labarque V, Trost SG, de Bourdeaudhuij I, Cardon G. Calibration and comparison of accelerometer cut points in preschool children. Int J Pediatr Obes. 2011; 6(22): $582-9$

12) Telford A, Salmon J, Jolley D, Crawford D. Reliability and Validity of Physical Activity Questionnaires for Children: The Children's Leisure Activities Study Survey (CLASS). Pediatr Exerc Sci. 2004; 16(1): 64-78 
13) Butte NF, Wong WW, Lee JS, Adolph AL, Puyau MR, Zakeri IF. Prediction of energy expenditure and physical activity in preschoolers. Med Sci Sports Exerc. 2014; 46(6): 121626

14) Evenson KR, Catellier DJ., Gill K, Ondrak KS, McMurray RG. Calibration of two objective measures of physical activity for children. J Sports Sci. 2008; 26(14): 1557-65

15) Troiano RP, Berrigan D, Dodd KW, Mâsse LC, Tilert T, McDowell M. Physical Activity in the United States Measured by Accelerometers. Med Sci Sports Exerc. 2008: 40(1): 181-8

16) Puyau MR, Adolph AL, Vohra FA, Butte NF. Validation and Calibration of Physical Activity Monitors in Children. Obes Res. 2002;10:150-157

17) Sirard JR, Trost SG, Pfeiffer KA, Dowda M, Pate RR. Calibration and evaluation of an objective measure of physical activity in preschool children. J Phys Act Health. 2005; 2(3): 345

18) Ludwig DS. Childhood obesity - the shape of things to come. New Engl J Med. 2007; 357(23): 2325-2327

19) Rauner A, Mess F, Woll A. The relationship between physical activity, physical fitness and overweight in adolescents: a systematic review of studies published in or after 2000. BMC Pediatr. 2013; 13(1): 19

20) Childhood Obesity Facts: Prevalence of Childhood Obesity in the United States, 2011-2012 . Centers for Disease Control and Prevention Division of Nutrition, Physical Activity, and obesity Wed site. http://www.cdc.gov/obesity/data/childhood.html. Updated June 19, 2015. Accessed August 23, 2015.

21) Daniels SR, Jacobson MS, McCrindle BW, Eckel RH, Sanner BM. American Heart Association Childhood Obesity Research Summit Executive Summary. Circulation. 2009; 119(15): 2114-2123

22) Rao G. Childhood obesity: highlights of AMA Expert Committee recommendations. Am Fam Physician. 2008; 78(1): 56-63

23) Zhao J, Grant SFA. Genetics of childhood obesity. J Obes. 2011; 2011

24) Cliff DP, Reilly JJ, Okely AD. Methodological considerations in using accelerometers to assess habitual physical activity in children aged 0-5 years. J Sci Med Sport. 2009; 12(5): 557-567

25) Centers for Disease Control and Prevention. State Indicator Report on Physical Activity, 2014. Atlanta, GA: U.S. Department of Health and Human Services, 2014 
26) Tremblay MS, LeBlanc AG, Carson V, et al. Canadian Physical Activity Guidelines for the Early Years (aged 0-4 years). Appl Physiol Nutr Metab. 2012;37(2): 345-356

27) Trost SG, Fees BS, Haar SJ, Murray AD, Crowe LK. Identification and Validity of Accelerometer Cut-Points for Toddlers. Obesity. 2012; 20: 2317-19

28) Esliger DW, Copeland JL, Barnes JD, Tremblay MS. Standardizing and optimizing the use of accelerometer data for free-living physical activity monitoring. J Phys Act Health. 2005; 3: 366-383

29) Penpraze V, Reilly JJ, MacLean CM, Montgomery C, Kelly LA, Paton JY. Monitoring of physical activity in young children: how much is enough?. Pediatr Exerc Sci. 2006; 18(4): 483

30) Rich C, Geraci M, Griffiths L, Sera F, Dezateux C, Cortina-Borja M. Quality control methods in accelerometer data processing: defining minimum wear time. PLoS One. 2013; 8(6).

31) Hislop J, Law J, Rush R. An investigation into the minimum accelerometry wear time for reliable estimates of habitual physical activity and definition of a standard measurement day in pre-school children. Physiol Meas. 2014; 35(11): 2213

32) Bornstein DB, Beets MW, Byun W, McIver K. Accelerometer-derived physical activity levels of preschoolers: a meta-analysis. J Sci Med Sport. 2011; 14(6): 504-511

33) Oliver M, Schofield GM, Kolt GS. Physical activity in preschoolers. Sports Med. 2007; 37 (12): 1045-1070

34) Borrud L, Chiappa M, Burt V, et al. National Health and Nutrition Examination Survey: national youth fitness survey plan, operations, and analysis, 2012. National Center for Health Statistics. Vital Health Stat 2(163) Vital and health statistics. Series 2, Data evaluation and methods research 163. 2014; 1-24.

35) Alhassan S, Sirard JR, Robinson TN. The effects of increasing outdoor play time on physical activity in Latino preschool children. Int J Pediatr Obes. 2007;2:153-158

36) Cardon G, De Bourdeaudhuij I. Comparison of pedometer and accelerometer measures of physical activity in preschool children. Pediatr Exerc Sci. 2007;19:205-214

37) Fisher A, Reilly JJ, Kelly LA, et al. Fundamental movement skills and habitual physical activity in young children. Med Sci Sports Exerc. 2005;37:684-688

38) Kelly LA, Reilly JJ, Fisher A, et al. Effect of socioeconomic status on objectively measured physical activity. Arch Dis Child. 2006;2005;91:35-38 
39) Cardon GM, De Bourdeaudhuij IMM. Are Preschool Children Active Enough? Objectively Measured Physical Activity Levels. Res Q Exerc Sport. 2008;79:326-332

40) Hinkley T, Crawford D, Salmon J, Okely AD, Hesketh K. Preschool children and physical activity: a review of correlates. Am J Prev Med. 2008; 34(5): 435-441

41) Healthy People 2020: Physical activity. Healthy People 2020 US Department of Health and Human Services Web site. file:///C:/Users/Anna/Documents/Thesis/Physical\%20activity/Physical\%20Activity\%20\%2 0Healthy\%20People\%202020.html Updated August 20, 2015. Accessed August 23, 2015

42) Dwyer GM, Hardy LL, Peat JK, Baur LA. The validity and reliability of a home environment preschool-age physical activity questionnaire (Pre-PAQ). Int J Behav Nutr Phy. 2011; 8(86)

43) wGT3X+/GT3X+ Manual. ActiGraph Web site. http://www.actigraphcorp.com/support/manuals/10284-2/ Accessed August 15, 2015

44) How are Cut Points Calculated?. ActiGraph Web site. https://help.theactigraph.com/entries/22225385-How-are-Cut-Points-Calculated- Published August 21, 2013. Accessed August 15, 2015

45) Vale S, Trost S, Ruiz J, Rego C, Moreira P, Mota J. Physical activity guidelines and preschooler's obesity status. INT J OBESITY. 2013;37:1352-1355

46) Colley RC, Garriguet D, Adamo KB, et al. Physical activity and sedentary behavior during the early years in Canada: A cross-sectional study. IJBNPA. 2013;10:54-54

47) Beets MW, Bornstein D, Dowda M, Pate RR. Compliance with national guidelines for physical activity in U.S. preschoolers: Measurement and interpretation. Pediatrics. 2011;127:658-664

48) Cardon GM, De Bourdeaudhuij IMM. Are Preschool Children Active Enough? Objectively Measured Physical Activity Levels. Res Q Exerc Sport. 2008;79:326-332

49) Mota J, Vale S, Santos R, Soares-Miranda L, Silva P. Compliance with physical activity guidelines in preschool children. J Sports Sci. 2010;28:603-608 


\section{Appendix A - Percent of Time in Activity}

Table 5. Percent of Time Participants Spend in Sedentary and Light to Vigorous Activity by Cut Point Set

\begin{tabular}{|c|c|c|c|c|}
\hline & $\begin{array}{c}\text { Mean \% of time } \\
\text { in Sedentary } \\
\text { Activity }\end{array}$ & $\begin{array}{c}\text { 95\% Confidence } \\
\text { Intervals }\end{array}$ & $\begin{array}{c}\text { Mean \% of time } \\
\text { in Light to } \\
\text { Vigorous } \\
\text { Activity }\end{array}$ & $\begin{array}{c}95 \% \text { confidence } \\
\text { Intervals }\end{array}$ \\
\hline Butte & 62.25 & $61.54-62.96$ & 37.75 & $37.04-38.46$ \\
\hline Sirard & 85.52 & $85.1-85.95$ & 14.47 & $14.05-14.9$ \\
\hline Evenson & 54.52 & $53.75-55.28$ & 45.48 & $44.72-46.24$ \\
\hline Puyau & 77.19 & $76.64-77.75$ & 22.8 & $22.25-23.36$ \\
\hline Pate & 77.19 & $76.64-77.75$ & 22.8 & $22.25-23.36$ \\
\hline 300 observations & \multicolumn{4}{|l}{} \\
\hline
\end{tabular}

